\title{
Letter to the Editor regarding "Dysphagia in non-intubated patients affected by COVID-19 infection"
}

\author{
Max Sarmet ${ }^{1}$ (D) Alessandra Dorça ${ }^{2} \cdot$ Jorge L. Zeredo $^{1} \cdot$ Antonio M. Esquinas $^{3}$
}

Received: 14 September 2021 / Accepted: 16 September 2021 / Published online: 24 September 2021

(c) The Author(s), under exclusive licence to Springer-Verlag GmbH Germany, part of Springer Nature 2021

\section{Dear Editor,}

We read the article by Grilli et al. [1] with great interest. The authors investigated the onset of swallowing disorders in patients with laboratory-confirmed COVID-19 infection to evaluate how the virus affected swallowing function. This is a valuable article that helps to shed light on a very important yet oftentimes overlooked symptom/sequela of COVID-19. There are a few points, however, that we believe deserve to be discussed further.

The first concern is the absence of videofluoroscopic swallowing study (VFSS), which currently represents the gold standard for dysphagia diagnosis and evaluation [2]. The authors justified its absence on several factors related to the COVID-19 pandemic. As a result, they opted instead for clinical evaluation.

The assessment of dysphagia in critically ill patients with COVID-19 is considered a necessary, albeit aerosol-generating, procedure [2]. Several recommendations on the dysphagia assessment have been published to reduce the exposure and potential contamination of healthcare workers [2] and postpone flexible endoscopic evaluation of swallowing (FEES) [3, 4]. On the other hand, VFSS has been considered a safer evaluation method, since it does not involve invasive instrumentation and it enables some distance between the assessor and the patient during the procedure [2]. Even in

This comment refers to the article available online at https://doi. org/10.1007/s00405-021-07062-3.

Max Sarmet

maxsarmet@gmail.com

1 Graduate Department of Health Sciences and Technologies, University of Brasília (UnB), Campus Universitário, s/n, Centro Metropolitano, Brasília, Brazil

2 Department of Health Sciences, Universidade Federal de Goiás, Goiânia, Brazil

3 Hospital General Universitario Morales Meseguer, Intensive Care Unit, Murcia, Spain risky procedures that cannot be postponed, some countermeasures can be introduced $[2,3]$. The authors stated that they chose clinical evaluation because it is a non-aerosol generating procedure. However, clinical evaluation represents a higher risk of transmission of COVID-19 when compared with VFSS [2].

Second, we noticed a lack of transparency in the demographic data. The authors stated that at the time of evaluation all patients had already overcome the acute phase of the COVID-19 and were therefore asymptomatic but still positive. The information of the mean duration of disease duration among the participants would bring important additional information for the interpretation of the results. The risk of COVID-19 transmission does not justify the absence of VFSS/FEES, as we can see in other similar studies, such as the post-COVID evaluation carried out by Lagier et al. [3]. Nevertheless, some adaptations could certainly be made using noninvasive imaging. Assessments could include methods such as ultrasound [5], which is an established tool for visualisation of head and neck anatomy, including structures implicated in swallowing. Ultrasound imaging could be adopted as an alternative tool for the objective assessment of swallowing.

The third major concern is the interpretation of the results. Clinical evaluation was considered positive for dysphagia when patients had symptoms like voice changes, cough, and/or desaturation at Volume-Viscosity Swallow Test [1]. Desaturation was interpreted in this case as a sign of bronchoaspiration and, in turn, of dysphagia. However, desaturation is a well-defined characteristic of the acute and post-acute conditions of COVID-19 and certainly influenced their results. Was the etiology of the observed desaturations due to dysphagia, COVID-19, or both? It was probably not by chance that the authors also observed that patients who were positively tested for dysphagia had more previous respiratory diseases $(62.5 \%)$ than non-dysphagic patients.

Finally, the lack of detailed information about non-invasive ventilation, pulmonary function tests and computed 
tomography of the lungs prevents readers from better understanding the influence of respiratory and swallowing outcomes. In our opinion, the lack of data on instrumental assessment of swallowing precludes any conclusion about the pathophysiology of the observed dysphagia which should be seen as a phenomenon to be explained. We greatly appreciate the researchers' efforts to research dysphagia even in an unfavorable setting and look forward to Grilli et al. conducting a future study using objective methods for the assessment of swallowing in COVID-19 patients.

Funding None.

\section{Declarations}

Conflicts of interest The authors report no conflicts of interest and certify that no funding has been received for this study and/or preparation of this manuscript.

\section{References}

1. Grilli GM, Giancaspro R, Del Colle A, Quarato CMI, Lacedonia D, Foschino Barbaro MP, Cassano M (2021) Dysphagia in non-intubated patients affected by COVID-19 infection. Eur Arch Otorhinolaryngol. https://doi.org/10.1007/s00405-02107062-3 (Epub ahead of print. PMID: 34468824; PMCID: PMC8408570)
2. Vergara J, Skoretz SA, Brodsky MB, Miles A, Langmore SE, Wallace S, Seedat J, Starmer HM, Bolton L, Clavé P, Freitas SV, Bogaardt H, Matsuo K, de Souza CM, Mourão LF (2020) Assessment, diagnosis, and treatment of dysphagia in patients infected with SARS-CoV-2: a review of the literature and international guidelines. Am J Speech Lang Pathol 29(4):2242-2253. https:// doi.org/10.1044/2020_AJSLP-20-00163 (Epub 2020 Sep 22 PMID: 32960646)

3. Lagier A, Melotte E, Poncelet M, Remacle S, Meunier P (2021) Swallowing function after severe COVID-19: early videofluoroscopic findings. Eur Arch Otorhinolaryngol 278(8):3119-3123. https://doi.org/10.1007/s00405-020-06522-6 (Epub 2021 Jan 3. PMID: 33388981; PMCID: PMC7778703)

4. Mattei A, Amy-de-la-Bretèque B, Crestani S, Crevier-Buchman L, Galant C, Hans S, Julien-Laferrière A, Lagier A, Lobryeau C, Marmouset F, Robert D, Woisard V, Giovanni A, French Society of Otorhinolaryngology, Head, Neck Surgery (SFORL); French Society of Phoniatrics, Laryngology (SFPL) (2020) Guidelines of clinical practice for the management of swallowing disorders and recent dysphonia in the context of the COVID-19 pandemic. Eur Ann Otorhinolaryngol Head Neck Dis 137(3):173-175. https:// doi.org/10.1016/j.anorl.2020.04.011 (Epub 2020 Apr 20. PMID: 32332004; PMCID: PMC7167576)

5. Allen JE, Clunie GM, Winiker K (2021) Ultrasound: an emerging modality for the dysphagia assessment toolkit? Curr Opin Otolaryngol Head Neck Surg 29(3):213-218. https://doi.org/10. 1097/MOO.0000000000000708 (PMID: 33741822; PMCID: PMC7611059)

Publisher's Note Springer Nature remains neutral with regard to jurisdictional claims in published maps and institutional affiliations. 